\title{
Evaluation of Vertical Guided Bone Regeneration Using a Particulate Form of Experimental Bioactive Glass in a Rabbit: A Case Report with Literature Review
}

\author{
Timur V. Melkumyan ${ }^{1 *}$, PhD, ScD; Nuritdin Kh. Kamilov ${ }^{1}$; \\ Fatima Yu. Daurova ${ }^{2}, \mathrm{PhD}, \mathrm{ScD}$; Angela D. Dadamova ${ }^{1}$ \\ ${ }^{1}$ Tashkent State Dental Institute, Tashkent, Uzbekistan \\ 2Peoples' Friendship University of Russia (RUDN University), Moscow, Russia
}

\begin{abstract}
Background: There are a large number of different types of bone-grafting materials that are used for the regeneration of atrophied alveolar ridges in order to make dental implantation possible. However, available surgical techniques and materials for bone augmentation do not contribute to the achievement of the desired reliable results and require a search for new solutions to an existing problem. A group of synthetic osteoplastic materials based on bioactive glass (BAG) may become a matter of choice in bone tissue regeneration because of special osteogenic properties. The aim of this study was to visually and histologically evaluate the behavior of an experimental BAG in rabbit tibia bone samples, which were collected from the animal 6 weeks after filling the bone defects.

Methods and Results: The observation was carried out on one outbred rabbit whose tibia bone defects were filled with an experimental osteoplastic material based on the BAG. The chemical composition of the experimental osteoplastic material included $\mathrm{SiO}_{2}(41 \%), \mathrm{Na}_{2} \mathrm{O}(21 \%), \mathrm{CaO}(28.5 \%), \mathrm{P}_{2} \mathrm{O}_{5}(6 \%), \mathrm{CaF}_{2}(1.5 \%), \mathrm{MgO}(1 \%), \mathrm{Al}_{2} \mathrm{O}_{3}(1 \%)$. For histological analysis, $\mathrm{H} \& \mathrm{E}$ staining of paraffin-embedded tissues was performed according to the standard technique. Light microscopy of tissue samples was performed using a Leitz HM-LUX microscope (Germany).

Six weeks after filling the bone defects, a strong bond between the augmented hard tissue and rabbit tibia was recognized. Also, a dense fusion of adjacent soft tissues with a newly formed bone without signs of chronic inflammation or graft particles in granular tissue was noted. Microscopic examination of the stained sections showed the presence of mature viable BT with a uniform distribution of osteocytes. Also, residual fragments of the degraded biomaterial surrounded by the fibers of a woven bone were revealed in several slices.

Conclusion: In accordance with the results of this experiment, it can be concluded that the usage of BAG related to the system $\mathrm{SiO} 2(41 \%)-\mathrm{Na} 2 \mathrm{O}(21 \%)-\mathrm{CaO}(28.5 \%)-\mathrm{P} 2 \mathrm{O} 5(6 \%)-\mathrm{CaF} 2(1.5 \%)-\mathrm{MgO}(1 \%)-\mathrm{Al} 2 \mathrm{O} 3(1 \%)$ may increase the volume of bone without application of barrier membrane. However, further research involving more animals needs to be done to estimate the scientific significance of the obtained data and to evaluate the mechanical properties of augmented bone.(International Journal of Biomedicine. 2021;11(3):308-314.)
\end{abstract}

Key Words: bioactive glass $\bullet$ bone tissue $\bullet$ vertical guided bone regeneration $\bullet$ osteogenesis

For citation: Melkumyan TV, Kamilov NKh, Daurova FYu, Dadamova AD. Evaluation of Vertical Guided Bone Regeneration Using a Particulate Form of Experimental Bioactive Glass in a Rabbit: A Case Report with Literature Review. International Journal of Biomedicine. 2021;11(3):308-314. doi:10.21103/Article11(3)_CR2

\section{Abbreviations}

BAG, bioactive glass; BT, bone tissue; GBR, guided bone regeneration; DO, distraction osteogenesis; VGBR, vertical GBR

\section{Introduction}

For the last few decades, mouth rehabilitation of patients with dental implants has become a widespread treatment modality in general practice. Such a rapid growth in this direction is caused by several factors, of which the most important and defining of the general tendency are the understanding and positive perception of patients who are considering dental implants as an effective and reliable treatment alternative for prosthetic replacement of missing teeth. ${ }^{(1,2)}$ 
In addition to patient comprehension, the growing number of field specialists also plays an important role in the development of dental implantology, because the outcome of implant therapy is highly dependent on correct digital treatment planning and effective cooperation of oral surgery and prosthodontics. Also, there are many other reasons related to the development and application of new materials, equipment, and technologies. ${ }^{(3,6)}$

However, despite the many positive aspects that promote the growth of dental rehabilitation through implants, the main obstacle to its spread is a deficiency of hard and soft tissues. In accordance with many studies, a sufficient amount of bone and attached gingiva around implants are the key prerequisites for their long service. ${ }^{(7,8)}$

In these particular cases, surgery for guided bone regeneration (GBR) is considered to be a viable opportunity for the patient and for the dental practitioner to place dental implants in an atrophied alveolar ridge. Data indicating the application of GBR first began to appear in the late 1980s. At that time, along with experimental studies in this direction, the usage of barrier membranes in clinical practice was going to be widespread. ${ }^{(9-11)}$

One of the most studied methods of surgical reconstruction of the alveolar ridge with barrier membranes is a two-stage surgery of horizontal augmentation. Data on the results of using this method has been published periodically for more than 30 years. For this period of time, every step of surgery had been optimized with consideration of possible complications, and successful outcomes of dental implant therapy were achieved..$^{(12-14)}$

However, taking into account cosmetic aspects of patient rehabilitation with dental implants, the need for VGBR in esthetic zones also takes precedence. But unlike horizontal augmentation of buccal resorption of the alveolar ridge, reconstructing its vertical dimensions is the most difficult task. ${ }^{(15-17)}$

A systematic review of the main database and relevant articles from refereed journals for the period from 1980 to 2005 revealed that VGBR of a severely resorbed alveolar ridge is a sensitive surgical procedure. Also, it was noted that the normal functioning of dental implants placed in augmented regions is less dependent on the amount of regenerated bone and more related to the quantity and quality of residual hard tissues, which are responsible for the primary and secondary stability of a fixture. ${ }^{(18)}$

In some clinical cases, existing methods of vertical augmentation with different types of materials make it possible to obtain positive outcomes of reconstructive surgery. However, every chosen treatment protocol is characterized by insufficient reproducibility and a high probability of postoperative complications..$^{(19,20)}$

The most commonly used method for vertical augmentation of the atrophied alveolar ridge, as well as with its horizontal reconstruction, remains GBR with the application of barrier membranes and particulate bone. However, as a dental practice has shown, to achieve satisfactory outcomes by using this technique, it is mandatory to use different types of titanium meshes or reinforced polytetrafluoroetylene membranes, but this can be a reason for wound dehiscence with subsequent infection, loss of graft material, and subsequent clinical failure. ${ }^{(21-23)}$

Using autogenous bone blocks for VGBR is not a widespread treatment modality because of a lot of shortcomings, such as an extended operative time, donor site morbidity and swelling, insufficient amount of graft and adjustment challenges, graft resorption, or absence of gradual vascular ingrowth. (24-27) As opposed to the surgery of autogenous bone harvesting, the practice of allogeneic bone blocks for the vertical reconstruction of the resorbed alveolar ridge is less invasive and might be promising, but still, they cause issues of disease transmission and immune rejection. ${ }^{(28-31)}$

Arelatively new method for 3-dimensional augmentation of the resorbed alveolar ridge is the bone ring technique. This type of one-stage VGBR surgery involves placing a dental implant through preliminary adjusted autogenous or allogeneic bone block graft of the corresponding shape. However, in accordance with the results of several studies, the efficacy of this approach may be more significant in the reconstruction of a single vertical bone deficiency, but further observations are yet to be done. ${ }^{(32)}$

Alternative surgery of DO is associated with mounting a special device on the alveolar ridge, which helps to gradually distract a transport bone segment for new bone formation in the traction zone. Even though using this kind of VGBR allows achieving a maximum possible natural bone growth with simultaneous expansion of the soft tissues, the method of DO can be characterized as less predictable with a high probability of postoperative complications. ${ }^{(33,34)}$

Considering these methods, it is quite clear that available VGBR techniques and materials for bone augmentation do not contribute to achieving the desired reliable results and require the search for new solutions to an existing problem.

In order to assess the potential of new materials that could be applied with confidence for regeneration of BT, preliminary in vitro and in vivo studies with the application of clinically relevant models are of prime concern. ${ }^{(35)}$

It is well known that autogenous bone has osteoconductive, osteoinductive, and osteogenic properties. However, the harvesting of autograft is the reason for additional trauma, and the bone itself is subject to rapid resorption. Widely used bone substitute materials based on hydroxyapatite and tricalcium phosphate have no property to biologically bond with soft tissues and require the use of collagen membranes. ${ }^{(36,37)}$

In contrast, there is a new group of synthetic osteoplastic materials based on $\mathrm{BAG}$, which possesses all the properties of an autogenous bone and can become a reliable alternative when planning a three-dimensional reconstruction of an atrophied alveolar ridge. ${ }^{(38)}$

The first melt-derived BAG was created thanks to the discovery of Larry Hench, who developed «Bioglass» based on oxides of silicon, sodium, calcium, and phosphorus. This material had the ability not only to mimic living BT, but also to induce the growth of a new bone. ${ }^{(39-42)}$

It should also be noted that over the years since the appearance of Bioglass 45S5, attempts are still being made to change its basic composition by adding some elements 
to modulate the necessary properties and to improve its biocompatibility. ${ }^{(43-46)}$

Therefore, the aim of this study was to visually and histologically evaluate the behavior of an experimental BAG in rabbit tibia bone samples, which were collected from the animal 6 weeks after filling the bone defects.

\section{Material and Methods}

In the present study, an observation was carried out on one outbred rabbit aged from 1.5 to 2 years and weighing $3.1 \mathrm{~kg}$, that was a participant in a parallel study, the purpose of which was the evaluation of osseointegration of hollow cylindrical zirconia implants placed in the rabbit tibia bones (Fig. 1 [a, b]). Because the animal was not sacrificed by the end of the time established for implant osseointegration, the bone defects (Fig. 2 [a, b]) caused by the removal of the implants were filled with an experimental osteoplastic material based on the BAG to assist the healing of bone (Fig. 2 [c,d]).

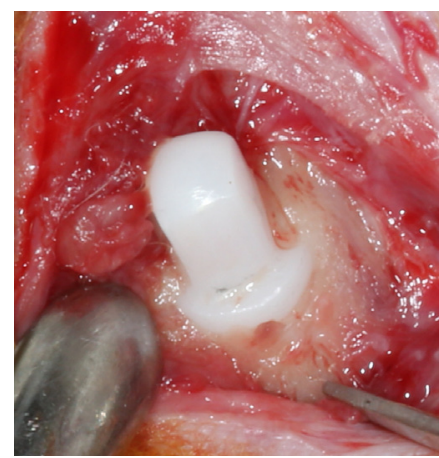

(a)

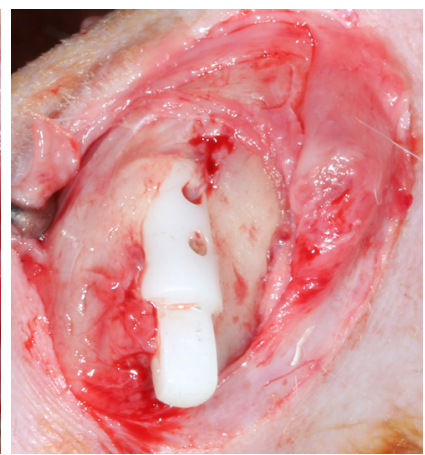

(b)
Fig.1. (a, b) Integrated hollow cylindrical zirconia implants (experimental) 6 weeks after implantation in rabbit tibia.

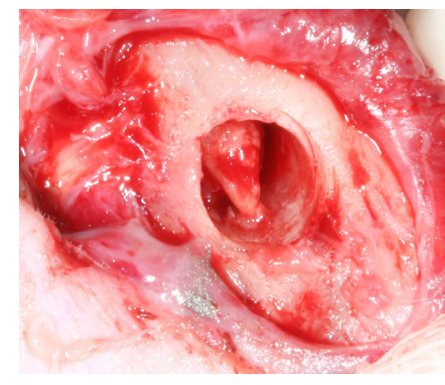

(a)

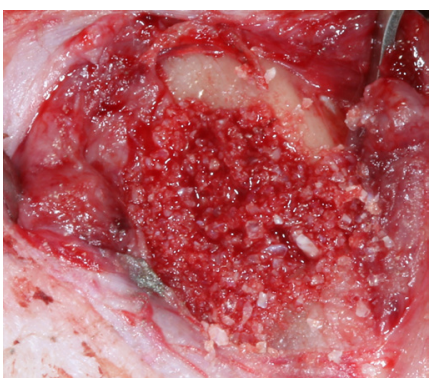

(c)

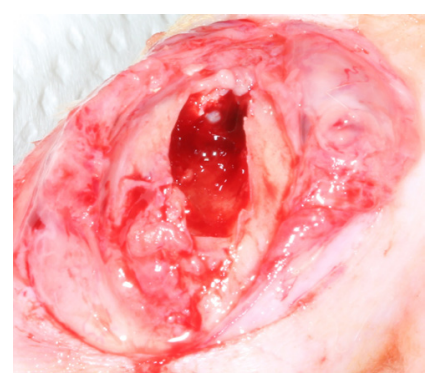

(b)

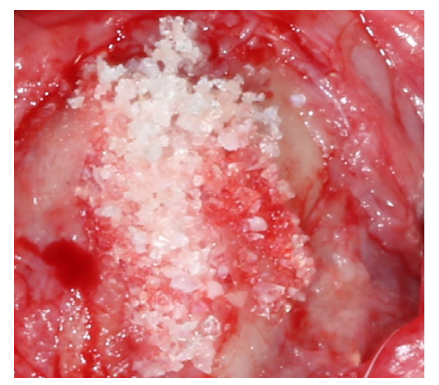

(d)
Fig.2. (a, b) Bone defects formed after removal of hollow cylindrical zirconia implants; $(c, d)$ Bone defects filled with particulate $B A G$
The experimental DAG was made traditionally by means of the melt-quenched method in a high-temperature furnace with silit rods at a maximum temperature of $1450{ }^{\circ} \mathrm{C}$ and holdtime for 1 hour, after which the molten mass was quenched into water. Formed granules of different sizes were ground in a ball mill and sieved in order to achieve particles with a size of $0.5-1 \mathrm{~mm}$. The chemical composition of the experimental osteoplastic material included $\mathrm{SiO}_{2}(41 \%), \mathrm{Na}_{2} \mathrm{O}(21 \%), \mathrm{CaO}$ (28.5\%), $\mathrm{P}_{2} \mathrm{O}_{5}(6 \%), \mathrm{CaF}_{2}(1.5 \%), \mathrm{MgO}(1 \%), \mathrm{Al}_{2} \mathrm{O}_{3}(1 \%)$.

The surgery was performed under general intravenous anesthesia using $1 \%$ sodium ethaminal solution in a dosage of $3 \mathrm{ml} / \mathrm{kg}$ body weight, which was combined with local infiltration anesthesia with $2-4 \mathrm{ml}$ of $2 \%$ lidocaine solution. Hair was removed in the areas of the planned intervention (area of the knee joints of both limbs) using scissors and a razor. After manipulation, the skin was treated with ethanol solution. The incision was made over the protruding part of the implant, which could be palpated under the skin. The length of the incision in each limb was about 4 centimeters. After elevation of the full-thickness flaps, the protruding part of the implant and part of the adjacent cortical bone were exposed (Fig. 1 [a, b]), and the implant was removed using a special instrument. Bone defects (Fig. 2 [a, b]) were filled in excess without the use of barrier membranes (Fig. 2 [c, d]). The amount of BAG material used in each site was around $1.5 \mathrm{~cm}^{3}$. The wound was closed with a single layer of sutures (Vicryl 5/0) (Fig. 3), after which the suture knots and surrounding skin were treated with a $5 \%$ alcohol solution of iodine.

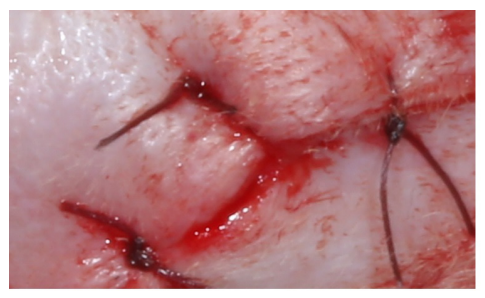

Fig.3. Simple interrupted sutures.

Reentry surgery was performed 6 weeks later. The operations were carried out according to a similar principle. Newly formed BT was collected using a trephine drill with an outer diameter of $5 \mathrm{~mm}$ at a speed of $1200 \mathrm{rpm}$ under constant saline cooling (Fig. 4 [a,b]).

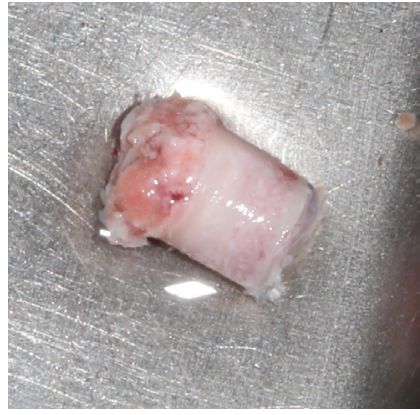

(a)

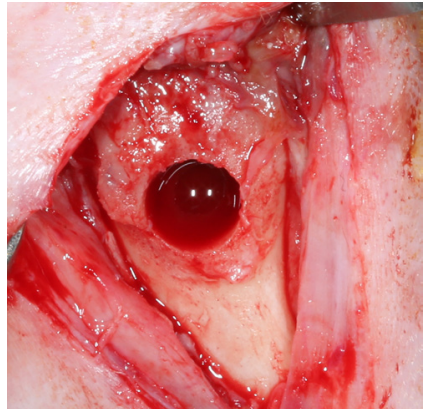

(b)
Fig.4. (a) A sample of a newly formed bone (b) Osteotomy after bone sampling with a trephine drill 
Collected BT samples were fixed in a $10 \%$ neutral buffered formalin solution, after which they were decalcified, washed, dried, and embedded in paraffin. Ready paraffin blocks were subjected to sectioning, and slices of a $4-6 \mu \mathrm{m}$ thickness were obtained and stained with hematoxylin and eosin. Light microscopy of tissue samples was performed using a Leitz HM-LUX microscope (Germany).

All experiments were performed in accordance with the Guide for the Care and Use of Laboratory Animals (The Institute of Laboratory Animal Resources, 1996). The study protocol was reviewed and approved by the Ethics Committee of Tashkent State Dental Institute.

\section{Results}

Before the surgery in the area of bone augmentation, the purpose of which was to identify the physiological response of soft and hard tissues to the implanted material, the health condition of the animal was assessed as normal. Visual examination of the limb skin showed normal healing without signs of purulent inflammation.

On palpation, regional lymph nodes were not enlarged. Also, in each limb, dense and immobile subcutaneous formations were present.

After making a longitudinal incision of the skin and periosteum over the protruding formations and elevating fullthickness flaps on the cortical surface of each tibia bone, an overgrowth of irregular size and shape was revealed, which differed from the natural bone in color and resembled a vitreous mass (Fig. $5[\mathrm{a}, \mathrm{b}]$ ). Also, when flaps were pushed away from the bone, a dense fusion of adjacent soft tissues with a newly formed bone without signs of chronic inflammation or graft particles in granular tissue was noted.

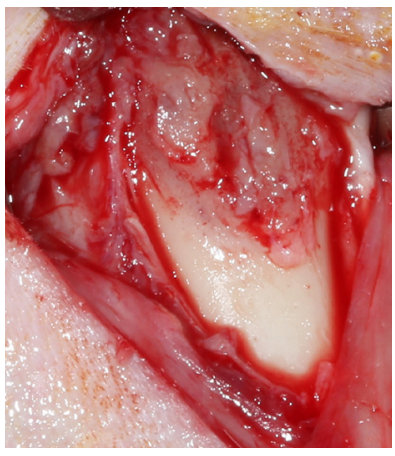

(a)

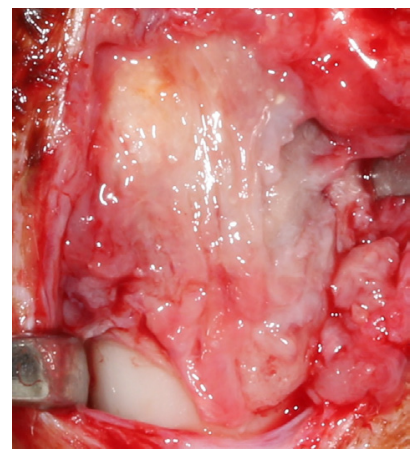

(b)
Fig.5. (a, b) Overgrowths of a newly formed bone in places of bone graft implantation.

During the bone sampling, a strong bond between the augmented hard tissue and rabbit tibia was recognized. Also, there was no separation of augmented hard tissue from the host or occurrence of cracking lines along the visible interface, which could be the cause of a drilling vibration.

Microscopic examination of the stained sections showed the presence of mature viable BT with a uniform distribution of osteocytes (Fig. 6 [a, b]). Also, residual fragments of the degraded biomaterial surrounded by the fibers of a woven bone were revealed in several slices (Fig. 6 [c, d]).

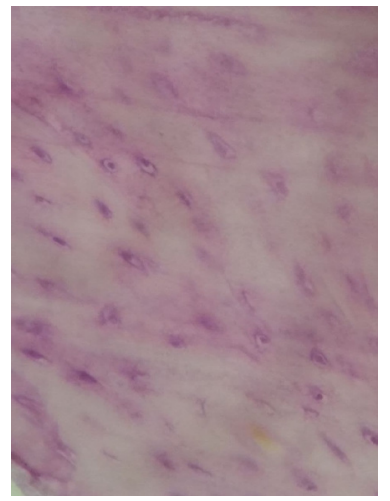

(a)

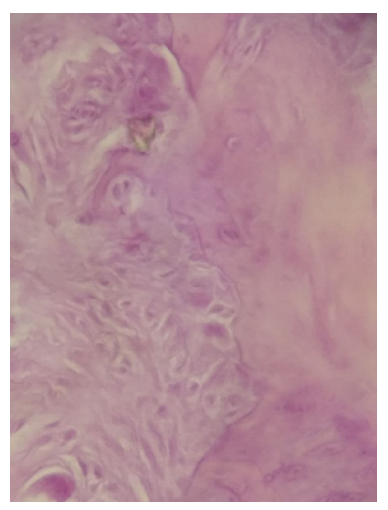

(c)

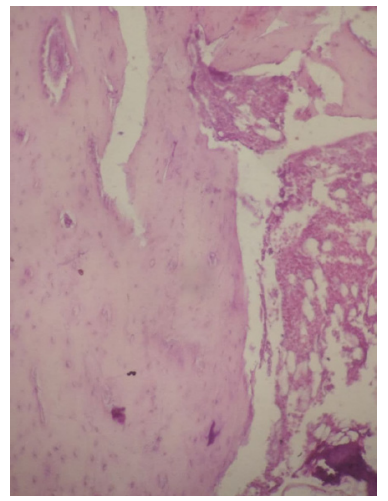

(b)

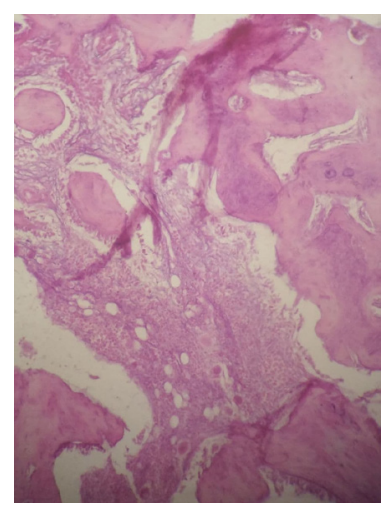

(d)
Fig.6. (a) Histological section of a bone collected from grafted site $(H \& E, \times 20)-$ newly formed bone with uniformly distributed osteocytes; (b) Histological section of a bone collected from a grafted site $(H \& E, \times 40)-$ non-mineralized osteoid matrix and newly formed bone; (c) Histological section of a bone collected from a grafted site $(H \& E$, $\times 20)$ - woven bone surrounds residual fragments of $B A G$; (d) Histological section of a bone collected from a grafted site $(H \& E, \times 40)-$ non-mineralized osteoid matrix at the interface with $B A G$

\section{Discussion}

3D reconstruction of an atrophied alveolar ridge is not a fully resolved issue in dental implantology because existing methods of vertical bone augmentation are not without drawbacks.

Considering the priority of development and implementation of new bone grafts for bone regeneration, the experimental animal research with the application of a clinically relevant model is one of the first steps in evaluating their safety and efficacy.

The rabbit tibia model is a widely used one because it allows analyzing the biological response on bone graft material and dental implant. This circumstance had served as the basis for choosing this experimental model in this study. ${ }^{(47-49)}$

To date, there is a large amount of data indicating a high efficiency of bone-grafting materials based on bioactive glass, which is successfully used in filling bone defects after 
removing benign neoplasms. Also, there are sources of data that confirm the positive behavior of this group of materials in the presence of pathogenic microflora. ${ }^{(50-54)}$

In the present experimental case study, a pronounced adhesion of a newly formed bone to the bone of the host was noted. Similar behavior of BAG bone grafts was observed in other studies, which confirmed the existence of its bonding ability to living tissues after the consolidation of the graft. . $^{(55-58)}$

Also, it should be noted that consolidation of the particulate bone graft and maturation of new BT occurred without using barrier membranes. This observation confirmed the ability of materials based on BAG to form a strong biological connection with soft tissues as well. ${ }^{(59)}$

Similar observations were made by other researchers, who did not find a significant difference between the usual grafting of bone defects using a BAG material and its application with a barrier membrane. ${ }^{(60)}$

Thus, in accordance with the results of this experiment, it can be concluded that the usage of $\mathrm{BAG}$ related to the system $\mathrm{SiO}_{2}(41 \%)-\mathrm{Na}_{2} \mathrm{O}(21 \%)-\mathrm{CaO}(28.5 \%)-\mathrm{P}_{2} \mathrm{O}_{5}(6 \%)-\mathrm{CaF}_{2}(1.5 \%)-$ $\mathrm{MgO}(1 \%)-\mathrm{Al}_{2} \mathrm{O}_{3}(1 \%)$ may increase the volume of bone without application of barrier membrane. However, further research involving more animals needs to be done to estimate the scientific significance of the obtained data and to evaluate the mechanical properties of augmented bone.

\section{Competing Interests} interests.

The authors declare that they have no competing

\section{References}

1. Zimmer CM, Zimmer WM, Williams J, Liesener J. Public awareness and acceptance of dental implants. Int $\mathrm{J}$ Oral Maxillofac Implants. 1992 Summer;7(2):228-32.

2. Elani HW, Starr JR, Da Silva JD, Gallucci GO. Trends in Dental Implant Use in the U.S., 1999-2016, and Projections to 2026. J Dent Res. 2018 Dec;97(13):1424-1430. doi: $10.1177 / 0022034518792567$.

3. Pope JD. Implantology Techniques toAvoid Complications. Decisions in Dentistry. February 2020;6(2):17-18,21-22.

4. Greenberg AM. Digital technologies for dental implant treatment planning and guided surgery. Oral Maxillofac Surg Clin North Am. 2015 May;27(2):319-40. doi: 10.1016/j. coms.2015.01.010.

5. Jabero M, Sarment DP. Advanced surgical guidance technology: a review. Implant Dent. 2006 Jun;15(2):135-42. doi: 10.1097/01.id.0000217790.68814.1e.

6. Xuereb M, Camilleri J, Attard NJ. Systematic review of current dental implant coating materials and novel coating techniques. Int J Prosthodont. 2015 Jan-Feb;28(1):51-9. doi: 10.11607/ijp.4124.

7. Schrott AR, Jimenez M, Hwang JW, Fiorellini J, Weber HP. Five-year evaluation of the influence of keratinized mucosa on peri-implant soft-tissue health and stability around implants supporting full-arch mandibular fixed prostheses. Clin Oral Implants Res. 2009 Oct;20(10):1170-7. doi: 10.1111/j.16000501.2009.01795.x.

8. Mittal Y, Jindal G, Garg S. Bone manipulation procedures in dental implants. Indian J Dent. 2016 Apr-Jun;7(2):86-94. doi: 10.4103/0975-962X.184650.

9. Liu J, Kerns DG. Mechanisms of guided bone regeneration: a review. Open Dent J. 2014 May 16;8:56-65. doi: $10.2174 / 1874210601408010056$.

10. Nyman S, Lindhe J, Karring T, Rylander H. New attachment following surgical treatment of human periodontal disease. J Clin Periodontol. 1982 Jul;9(4):290-6. doi: 10.1111/j.1600-051x.1982.tb02095.x.

11. Caballé-Serrano J, Munar-Frau A, Ortiz-Puigpelat O, Soto-Penaloza D, Peñarrocha $\mathrm{M}$, Hernández-Alfaro $\mathrm{F}$. On the search of the ideal barrier membrane for guided bone regeneration. J Clin Exp Dent. 2018 May 1;10(5):e477-e483. doi: $10.4317 /$ jced.54767. PMID: 29849973;

12. Wessing B, Emmerich M, Bozkurt A. Horizontal Ridge Augmentation with a Novel Resorbable Collagen Membrane: A Retrospective Analysis of 36 Consecutive Patients. Int J Periodontics Restorative Dent. 2016 Mar-Apr;36(2):179-87. doi: $10.11607 /$ prd.2065.

13. Urban IA, Nagursky H, Lozada JL, Nagy K. Horizontal ridge augmentation with a collagen membrane and a combination of particulated autogenous bone and anorganic bovine bone-derived mineral: a prospective case series in 25 patients. Int J Periodontics Restorative Dent. 2013 MayJun;33(3):299-307. doi: 10.11607/prd.1407.

14. Jensen AT, Jensen SS, Worsaae N. Complications related to bone augmentation procedures of localized defects in the alveolar ridge. A retrospective clinical study. Oral Maxillofac Surg. 2016 Jun;20(2):115-22. doi: 10.1007/s10006-016-0551-8. 15. Rocchietta I, Fontana F, Simion M. Clinical outcomes of vertical bone augmentation to enable dental implant placement: a systematic review. J Clin Periodontol. 2008 Sep;35(8 Suppl):203-15. doi: 10.1111/j.1600-051X.2008.01271.x.

16. Merli M, Migani M, Bernardelli F, Esposito M. Vertical bone augmentation with dental implant placement: efficacy and complications associated with 2 different techniques. A retrospective cohort study. Int J Oral Maxillofac Implants. 2006 Jul-Aug;21(4):600-6.

17. Merli M, Migani M, Esposito M. Vertical ridge augmentation with autogenous bone grafts: resorbable barriers supported by ostheosynthesis plates versus titanium-reinforced barriers. A preliminary report of a blinded, randomized controlled clinical trial. Int J Oral Maxillofac Implants. 2007 May-Jun;22(3):373-82.

18. Aghaloo TL, Moy PK. Which hard tissue augmentation techniques are the most successful in furnishing bony support for implant placement? Int J Oral Maxillofac Implants. 2007;22 Suppl:49-70. Erratum in: Int J Oral Maxillofac Implants. 2008 Jan-Feb;23(1):56.

19. Jensen AT, Jensen SS, Worsaae N. Complications related to bone augmentation procedures of localized defects in the alveolar ridge. A retrospective clinical study. Oral Maxillofac Surg. 2016 Jun;20(2):115-22. doi: 10.1007/s10006-016-0551-8. 20. Aloy-Prósper A, Peñarrocha-Oltra D, PeñarrochaDiago M, Peñarrocha-Diago $M$. The outcome of intraoral onlay block bone grafts on alveolar ridge augmentations: a systematic review. Med Oral Patol Oral Cir Bucal. 2015 Mar 1;20(2):e251-8. doi: 10.4317/medoral.20194.

21. Urban IA, Saleh MHA, Ravidà A, Forster A, Wang HL, Barath Z. Vertical bone augmentation utilizing a titaniumreinforced PTFE mesh: A multi-variate analysis of influencing factors. Clin Oral Implants Res. 2021 Jul;32(7):828-839. doi: 10.1111/clr.13755. 
22. Cucchi A, Vignudelli E, Fiorino A, Pellegrino G, Corinaldesi G. Vertical ridge augmentation (VRA) with Tireinforced d-PTFE membranes or Ti meshes and collagen membranes: 1-year results of a randomized clinical trial. Clin Oral Implants Res. 2021 Jan;32(1):1-14. doi: 10.1111/ clr. 13673 .

23. Cucchi A, Vignudelli E, Napolitano A, Marchetti C, Corinaldesi G. Evaluation of complication rates and vertical bone gain after guided bone regeneration with nonresorbable membranes versus titanium meshes and resorbable membranes. A randomized clinical trial. Clin Implant Dent Relat Res. 2017 Oct;19(5):821-832. doi: 10.1111/cid.12520.

24. Tessier P, Kawamoto H, Posnick J, Raulo Y, Tulasne JF, Wolfe SA. Complications of harvesting autogenous bone grafts: a group experience of 20,000 cases. Plast Reconstr Surg. 2005 Oct;116(5 Suppl):72S-73S. doi: 10.1097/01. prs.0000173841.59063.7e.

25. Maiorana C, Beretta M, Salina S, Santoro F. Reduction of autogenous bone graft resorption by means of bio-oss coverage: a prospective study. Int J Periodontics Restorative Dent. 2005 Feb;25(1):19-25. PMID: 15736775.

26. Sakkas A, Ioannis K, Winter K, Schramm A, Wilde F. Clinical results of autologous bone augmentation harvested from the mandibular ramus prior to implant placement. An analysis of 104 cases. GMS Interdiscip Plast Reconstr Surg DGPW. 2016 Oct 6;5:Doc21. doi: 10.3205/iprs000100.

27. Kaing L, Grubor D, Chandu A. Assessment of bone grafts placed within an oral and maxillofacial training programme for implant rehabilitation. Aust Dent J. 2011 Dec;56(4):40611. doi: 10.1111/j.1834-7819.2011.01369.x.

28. Draenert FG, Kämmerer PW, Berthold M, Neff A. Complications with allogeneic, cancellous bone blocks in vertical alveolar ridge augmentation: prospective clinical case study and review of the literature. Oral Surg Oral Med Oral Pathol Oral Radiol. 2016 Aug;122(2):e31-43. doi: 10.1016/j. oooo.2016.02.018.

29. Starch-Jensen T, Deluiz D, Tinoco EMB. Horizontal Alveolar Ridge Augmentation with Allogeneic Bone Block Graft Compared with Autogenous Bone Block Graft: a Systematic Review. J Oral Maxillofac Res. 2020 Mar 31;11(1):e1. doi: 10.5037/jomr.2020.11101.

30. Ang CY, Yew AK, Tay DK, Chia SL, Yeo SJ, Lo NN, Chin PL. Reducing allograft contamination and disease transmission: intraosseous temperatures of femoral head allografts during autoclaving. Singapore Med J. 2014 Oct;55(10):526-8. doi: 10.11622/smedj.2014135.

31. Fishman JA, Greenwald MA, Grossi PA. Transmission of infection with human allografts: essential considerations in donor screening. Clin Infect Dis. 2012 Sep;55(5):720-7. doi: $10.1093 /$ cid/cis519.

32. Giraddi GB, Saifi AM. Bone Ring Augmentation Around Immediate Implants: A Clinical and Radiographic Study. Ann Maxillofac Surg. 2017 Jan-Jun;7(1):92-97. doi: 10.4103/ams. ams_58_17.

33. Saulacić N, Somosa Martín M, de Los Angeles Leon Camacho M, García García A. Complications in alveolar distraction osteogenesis: A clinical investigation. J Oral Maxillofac Surg. 2007 Feb;65(2):267-74. doi: 10.1016/j. joms.2006.03.049.

34. Ettl T, Gerlach T, Schüsselbauer T, Gosau M, Reichert TE, Driemel O. Bone resorption and complications in alveolar distraction osteogenesis. Clin Oral Investig. 2010 Oct;14(5):481-9. doi: 10.1007/s00784-009-0340-y.
35. Zhang Z, Gan Y, Guo Y, Lu X, Li X. Animal models of vertical bone augmentation (Review). Exp Ther Med. 2021 Sep;22(3):919. doi: 10.3892/etm.2021.10351.

36. Roberts TT, Rosenbaum AJ. Bone grafts, bone substitutes and orthobiologics: the bridge between basic science and clinical advancements in fracture healing. Organogenesis. 2012 Oct-Dec;8(4):114-24. doi: 10.4161/org.23306.

37. Bellucci D, Sola A, Cannillo V. Hydroxyapatite and tricalcium phosphate composites with bioactive glass as second phase: State of the art and current applications. J Biomed Mater Res A. 2016 Apr;104(4):1030-56. doi: 10.1002/ jbm.a.35619.

38. Karadjian M, Essers C, Tsitlakidis S, Reible B, Moghaddam A, Boccaccini AR, Westhauser F. Biological Properties of Calcium Phosphate Bioactive Glass Composite Bone Substitutes: Current Experimental Evidence. Int J Mol Sci. 2019 Jan 14;20(2):305. doi: 10.3390/ijms20020305.

39. Hench LL, West JK. Biological applications of bioactive glasses. Life Chem Reports. 1996;13:187-241.

40. Hench LL, Xynos ID, Buttery LD, Polak JM. Bioactive materials to control cell cycle. Mater Res Innovations. 2000;3:313-23.

41. Xynos ID, Hukkanen MV, Batten JJ, Buttery LD, Hench LL, Polak JM. Bioglass 45S5 stimulates osteoblast turnover and enhances bone formation In vitro: implications and applications for bone tissue engineering. Calcif Tissue Int. 2000 Oct;67(4):321-9. doi: 10.1007/s002230001134.

42. Xynos ID, Edgar AJ, Buttery LD, Hench LL, Polak JM. Ionic products of bioactive glass dissolution increase proliferation of human osteoblasts and induce insulin-like growth factor II mRNA expression and protein synthesis. Biochem Biophys Res Commun. 2000 Sep 24;276(2):461-5. doi: 10.1006/bbrc.2000.3503.

43. Tripathi H, Rath C, Kumar AS, Manna PP, Singh SP. Structural, physico-mechanical and in-vitro bioactivity studies on $\mathrm{SiO}_{2}-\mathrm{CaO}-\mathrm{P}_{2} \mathrm{O}_{5}-\mathrm{SrO}-\mathrm{Al}_{2} \mathrm{O}_{3}$ bioactive glasses. Mater Sci Eng C Mater Biol Appl. 2019 Jan 1;94:279-290. doi: 10.1016/j. msec.2018.09.041.

44. Deliormanl AM. Synthesis and characterization of cerium- and gallium-containing borate bioactive glass scaffolds for bone tissue engineering. J Mater Sci Mater Med. 2015 Feb;26(2):67. doi: 10.1007/s10856-014-5368-0.

45. Bejarano J, Boccaccini AR, Covarrubias C, Palza H. Effect of $\mathrm{Cu}$ - and $\mathrm{Zn}$-Doped Bioactive Glasses on the In Vitro Bioactivity, Mechanical and Degradation Behavior of Biodegradable PDLLA Scaffolds. Materials (Basel). 2020 Jun 29;13(13):2908. doi: 10.3390/ma13132908.

46. Tabia Z, El Mabrouk Kh, Bricha M, Nouneh Kh. Mesoporous bioactive glass nanoparticles doped with magnesium: drug delivery and acellular in vitro bioactivity. RSC Advances. 2019;9(22):12232-12246. doi: 10.1039/C9RA01133A

47. Kim YJ, de Molon RS, Horiguti FR, Contador GP, Coelho MA, Mascarenhas VI, de Souza Faloni AP, Cirelli JA, Sendyk WR. Vertical Bone Augmentation Using Deproteinized Bovine Bone Mineral, Absorbable Collagen Sponge, and Recombinant Human Bone Morphogenetic Protein-2: An In Vivo Study in Rabbits. Int J Oral Maxillofac Implants. 2018 May/June;33(3):512-522. doi: 10.11607/jomi.5959.

*Corresponding author: Prof. Timur V. Melkumyan, PhD, ScD. Tashkent State Dental Institute. Tashkent, Uzbekistan. E-mail. t.dadamov@gmail.com 
48. Queiroz TP, de Molon RS, Souza FÁ, Margonar R, Thomazini AH, Guastaldi AC, Hochuli-Vieira E. In vivo evaluation of $\mathrm{cp}$ Ti implants with modified surfaces by laser beam with and without hydroxyapatite chemical deposition and without and with thermal treatment: topographic characterization and histomorphometric analysis in rabbits. Clin Oral Investig. 2017 Mar;21(2):685-699. doi: 10.1007/s00784-016-1936-7.

49. Faeda RS, Tavares HS, Sartori R, Guastaldi AC, Marcantonio E Jr. Biological performance of chemical hydroxyapatite coating associated with implant surface modification by laser beam: biomechanical study in rabbit tibias. J Oral Maxillofac Surg. 2009 Aug;67(8):1706-15. doi: 10.1016/j.joms.2009.03.046.

50. Stoor P, Apajalahti S, Kontio R. Regeneration of Cystic Bone Cavities and Bone Defects With Bioactive Glass S53P4 in the Upper and Lower Jaws. J Craniofac Surg. 2017 Jul;28(5):1197-1205. doi: 10.1097/SCS.0000000000003649. PMID: 28538076.

51. Malat TA, Glombitza M, Dahmen J, Hax PM, Steinhausen E. The Use of Bioactive Glass S53P4 as Bone Graft Substitute in the Treatment of Chronic Osteomyelitis and Infected NonUnions - a Retrospective Study of 50 Patients. Z Orthop Unfall. 2018 Apr;156(2):152-159. doi: 10.1055/s-0043-124377.

52. Trishala A, Jacob C. The anti-bacterial activity of bioactive glass. International Journal of Advanced Research. 2016;4(6):1070-1077

53. Zhang D, Leppäranta O, Munukka E. Antibacterial effects and dissolution behaviour of six bioactive glasses. J Control Release. 2009;139:118-26.

54. Lindfors N, Geurts J, Drago L, Arts JJ, Juutilainen V, Hyvönen P, Suda AJ, Domenico A, Artiaco S, Alizadeh
C, Brychcy A, Bialecki J, Romanò CL. Antibacterial Bioactive Glass, S53P4, for Chronic Bone Infections - A Multinational Study. Adv Exp Med Biol. 2017;971:81-92. doi: 10.1007/5584_2016_156. Erratum in: Adv Exp Med Biol. 2017;971:115-116.

55. Axrap A, Wang J, Liu Y, Wang M, Yusuf A. Study on adhesion, proliferation and differentiation of osteoblasts promoted by new absorbable bioactive glass injection in vitro. Eur Rev Med Pharmacol Sci. 2016 Nov;20(22):4677-4681.

56. Nordström EG, Sánchez Muñoz OL. Physics of bone bonding mechanism of different surface bioactive ceramic materials in vitro and in vivo. Biomed Mater Eng. 2001;11(3):221-31.

57. Margonar R, Queiroz TP, Luvizuto ER, Marcantonio É, Lia RC, Holzhausen M, Marcantonio-Júnior É. Bioactive glass for alveolar ridge augmentation. J Craniofac Surg. 2012 May;23(3):e220-2. doi: 10.1097/SCS.0b013e31824de5a4.

58. Wang SA, Chen AY, Yu ZE, Huang ZJ, Wao YM. Alveolar ridge augmentation with bioactive glass ceramics: a histological study. J Oral Rehabil. 1989 May;16(3):229-39. doi: 10.1111/j.1365-2842.1989.tb01337.x.

59. Rahaman MN, Day DE, Bal BS, Fu Q, Jung SB, Bonewald LF, Tomsia AP. Bioactive glass in tissue engineering. Acta Biomater. 2011 Jun;7(6):2355-73. doi: 10.1016/j. actbio.2011.03.016.

60. Yukna RA, Evans GH, Aichelmann-Reidy MB, Mayer ET. Clinical comparison of bioactive glass bone replacement graft material and expanded polytetrafluoroethylene barrier membrane in treating human mandibular molar class II furcations. J Periodontol. 2001 Feb;72(2):125-33. doi: 10.1902/jop.2001.72.2.125. 